\title{
Challenges in the Diagnosis and Assessment in Patients with Tourette Syndrome and Comorbid Obsessive-Compulsive Disorder
}

\author{
Natalia Szejko iD ${ }^{1-4}$ \\ Kirsten R Müller-Vahl ${ }^{2}$ \\ 'Division of Neurocritical Care, \\ Department of Neurology, Yale \\ University, New Haven, CT, USA; ${ }^{2}$ Clinic \\ of Psychiatry, Socialpsychiatry and \\ Psychotherapy, Hannover Medical School, \\ Hannover, Germany; ${ }^{3}$ Department of \\ Neurology, Medical University of \\ Warsaw, Warsaw, Poland; ${ }^{4}$ Department \\ of Bioethics, Medical University of \\ Warsaw, Warsaw, Poland
}

\begin{abstract}
Tourette syndrome (TS) is characterized by the presence of vocal and motor tics with an onset in childhood. In almost $80 \%$ of patients psychiatric comorbidities coexist, particularly, attention deficit/hyperactivity disorder (ADHD), obsessive-compulsive disorder (OCD) or behavior (OCB), depression, anxiety, rage attacks, and self-injurious behaviour (SIB). In this review, we discuss current state of the art regarding diagnosis and assessment of tics and OCD in patients with TS as well as challenges related to differential diagnosis between tics and OCD-related phenomena based on a systematic literature search. While in most cases clinical symptoms can be easily classified as either tics or OCB/OCD, some phenomena lay on the frontier between tics and compulsions/obsessions. For example, compulsions may resemble tics and, vice versa, sequences of motor tics may be misdiagnosed as compulsions. Accordingly, the terms "compulsive tics" and "cognitive tics" have been introduced. The most common and typical OCD symptom in patients with TS are "just right" phenomena, which also may show an overlap with tics, since patients may perform tics repeatedly until this feeling is achieved. Similarly, repetitive behaviors in patients with TS may manifest in a more "tic-like" or a more "OCD-like" type. Furthermore, SIB shows similarities with both tics and OCD. Until today, it is unclear how to classify this symptom best, although from most recent research a closer relationship between SIB and tics is suggested. In this review, in addition, we illustrate differences of the clinical spectrum of OCD in patients with TS compared to those with "pure OCD" without tics. To assess tics, the revised version of the Yale Global Tic Severity Scale (YGTSS-R) should be used, while for the assessment of OCD, the Yale Brown Obsessive Compulsive Disorder Scale (Y-BOCS) is recommended. Finally, we briefly summarize treatment strategies for tics and OCB/OCD in patients with TS.
\end{abstract}

Keywords: Tourette syndrome, obsessive-compulsive disorder, obsessive-compulsive behavior, comorbidities, tics

\section{Introduction}

According to DSM-5, Tourette syndrome (TS) is defined by the presence of at least one vocal and multiple motor tics persisting for more than 1 year with childhood onset. In almost $80 \%$ of patients, psychiatric comorbidities co-occur, the most frequently being attention deficit/hyperactivity disorder (ADHD), obsessive-compulsive behavior (OCB) or obsessive-compulsive disorder (OCD), depression, anxiety, rage attacks, and self-injurious behavior (SIB). ${ }^{1,2}$ The prevalence of TS ranges - depending on age - from $0.3 \%$ to $1 \% .^{3-5}$ Tics are sudden, rapid, recurrent, non-rhythmic motor movements or vocalizations. ${ }^{6}$ Alternatively
Correspondence: Natalia Szejko

Division of Neurocritical Care,

Department of Neurology, Yale

University, I5 Lock Street, New Haven,

CT, USA

Email natalia.szejko@yale.edu 
to the term vocal tics, the name phonic tic is used. Both motor and vocal tics can be further divided into simple and complex tics. Depending on the movement pattern motor tics, in addition, can be classified as tonic, clonic, or dystonic tics. In addition, some specific types of complex tics include echolalia (repetition of sounds, words or phrases pronounced by others), echopraxia (repetition of gestures executed by others), palilalia (spontaneous repetition of one's own sounds, words or phrases sometime resembling stuttering or speech blocking tics), palipraxia (repetition of one's own gestures), coprolalia (shouting of obscene words or phrases), and copropraxia (execution of obscene postures or gestures). Finally, tics are typically characterized by brief preceding premonitory sensations, temporal suppressibility, and a rostro-caudal distribution.

While in the majority of patients the diagnosis of a primary tic disorder is easy to make, in some patients the differential diagnosis is more difficult and complex. Motor tics must be differentiated not only from other hyperkinetic movement disorders, such as stereotypies, myoclonus, paroxysmal disorders, and epileptic seizures, but also hyperactivity due to ADHD and repetitive behaviors and rituals belonging to the OCD spectrum, and, finally, from functional movements. Interestingly, the clinical spectrum of OCB/OCD in TS differs from symptoms in pure OCD. This has been described as "tic-related OCD" mainly associated with "just right" phenomena. ${ }^{7,8}$ However, tics and "just right" phenomena may also occur coincidentally.

In this review we want to give recommendations for the diagnosis and assessment of tics and OCD in patients with TS. To identify all relevant articles, we conducted a systematic review yielding to find publications reporting about OCD phenomena in TS. Furthermore, recommendations given by the European Society for the Study of Tourette Syndrome (ESSTS) have been taken into consideration. ${ }^{9}$ Finally, we address challenges that one could encounter in the management of patients with overlapping tics and obsessions and/or compulsions. In this regard, we also outline differences between the OCB/ OCD spectrum in TS compared to pure OCD (without tics) and briefly highlight differences in therapeutic interventions.

\section{Methodology}

We conducted both a systematic as well as a narrative review of the most important aspects related to $\mathrm{OCB} /$ OCD in TS. Our systematic approach was based on the search in PubMed, Ovid, Web of Science, Embase and APA Psych Info conducted on February 08, 2021. We searched for articles examining the coexistence of TS and $\mathrm{OCB} / \mathrm{OCD}$ using the search terms "tics" AND/OR "Tourette" AND/OR "obsessive-compulsive disorder" AND/OR "OCD” AND/OR "obsession" AND/OR "compulsion". Reviews and meta-analyses in the area were further searched for relevant citations.

Titles and abstracts of the studies obtained through this search were examined by both authors in order to determine article inclusion. Each article was also checked for further potential references. Discrepancies were addressed by the authors through discussion. Eligibility for the systematic review was based on the following criteria: (1) studies involving patients with TS and OCD, (2) original articles, and (3) studies in humans. Articles were excluded based on the following criteria (1) meta-analyses or review papers, (2) not investigating patients with TS and OCD, and (3) animal or other preclinical studies. Several studies included data previously reported elsewhere. Data collected on each article included year, study design, number of subjects with TS and/or OCD, mean correlates of OCD in TS and the most important characteristics of OCD in TS in comparison with $\mathrm{OCD} / \mathrm{OCB}$. As a result, we identified 628 articles, out of which 57 have been included in this review. Our search strategy is illustrated in a PRISMA flow diagram (Figure 1). While in the subsequent review, we included only the most relevant studies, additionally an extensive list of all 57 publications including the most important findings is shown in Supplementary Table 1.

\section{Diagnosis and Assessment of Tics in Tourette Syndrome}

According to the guidelines published by ESSTS, ${ }^{9}$ the diagnosis of TS should be made according to newest DSM criteria. This includes the exclusion of other phenomena resembling tics as well as secondary tic disorders. Tics are characterized by a number of clinical phenomena useful to distinguish them from other neurological and psychiatric symptoms. In the majority of patients, tics are proceeded by premonitory urges defined as an uncomfortable sensation of twinging, itching, or stretching, partially or completely relieved by the tic execution. This sensation is reported to last only a fraction of a second and occurs immediately before the tic. Based on clinical experience it is believed that the topographic distribution of premonitory urges stays in line with the tic localization. Typically, 


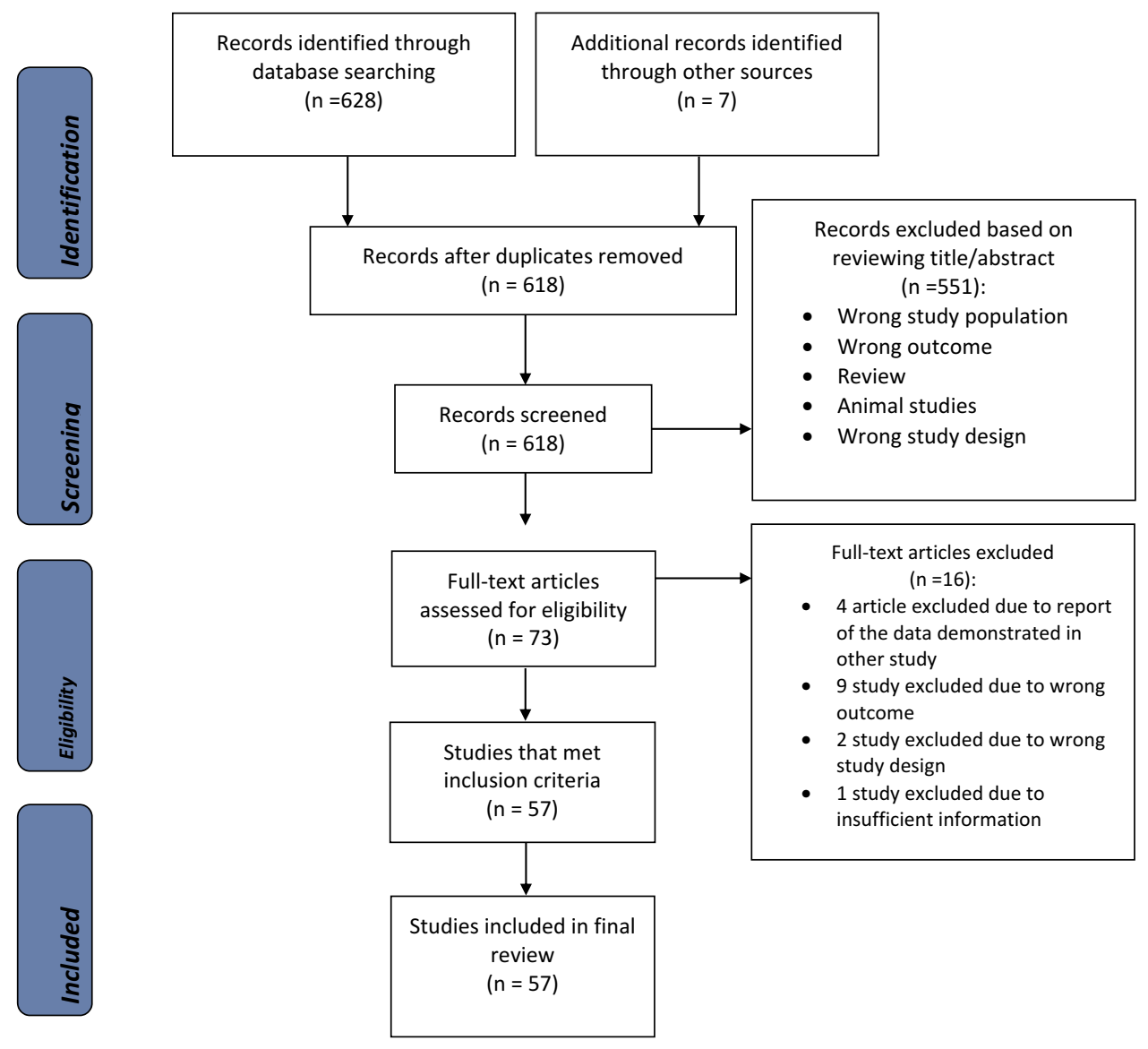

Figure I PRISMA flow diagram ${ }^{\text {Moher }} 2009$.

patients can suppress their tics for a short period of time ranging from seconds to minutes..$^{10}$ Noteworthy, the presence of premonitory urges and tics suppressibility are highly age dependent as many children do not report premonitory sensations and feel unable to suppress their tics voluntarily.

Another important characteristic is that tics are influenced by environmental factors. The majority of patients reports a temporarily tic increase during stress, emotional tension, but also when talking about tics and seeing others with tics, while tics typically decrease with concentration and relaxation. Finally, the course of tics in TS is typically waxing and waning with respect to frequency, number, intensity, complexity, and phenomenology. The typical age at onset of tics is 5-7 years. ${ }^{11}$ In most patients, simple tics proceed complex tics and motor tics usually start before vocal tics. ${ }^{1}$ In almost $70 \%$ of cases, peak tic severity is experienced in the early adolescence between 10 and 12 years of age. ${ }^{11-13}$ Thereafter, tics spontaneously improve in the vast majority of patients, but may persist into adulthood. ${ }^{12-14}$
The assessment of tics is often challenging due to their waxing and waning nature, suppressibility of tics, as well as great variability regarding their impact on quality of life. It is therefore advisable to take all available information into consideration, including interview, clinical examination, and reports by families and caregivers and - if possible and in more complex cases - home-made video recordings. Because of these well-known difficulties in assessing tics, during the last years several different measurements have been suggested for tic assessment. The authors of a systematic review published in 2017 classified available tic rating scales as "recommended", "suggested", and "listed" 15 and recommended the following rating scales: the Yale Global Tic Severity Scale (YGTSS), ${ }^{16}$ the Tourette Syndrome Clinical Global Impression (TS-CGI), ${ }^{17}$ the Tourette's Disorder Scale (TDS) ${ }^{18}$ the Shapiro Tourette syndrome Severity Scale (STSS), ${ }^{19}$ and the Premonitory Urges for Tics Scale (PUTS). ${ }^{20}$ Furthermore, six scales were rated as "suggested" and another five as "listed" (for more details refer to Martino et $\mathrm{al}^{15}$ ). Anyhow, the gold 
standard to measure tic severity is the YGTSS. However, there is general agreement to use only the "total tic score" (TTS, range, 0-50) of the YGTSS to assess tics. To overcome - at least in part - limitations of the YGTSS, in 2018, McGuire et al $^{21}$ introduced a revised version of the YGTSS (YGTSS-R). Although only recently we were able to show that further improvements are needed - particularly regarding the complexity of the measurement ${ }^{22}$ - in future studies the YGTSS-R (instead of the YGTSS) should be used. Most widely used scales helpful in the diagnosis and assessment of tics are summarized in Table 1.

\section{Characteristics of Obsessive-Compulsive Disorder in Patients with Tourette Syndrome}

In TS, psychiatric comorbidities are the rule rather than the exception and occur in almost $80 \%$ of patients. ${ }^{1,23,24} \mathrm{OCB} /$ OCD is - beside ADHD - the most common comorbid psychiatric comorbidity, particularly in adults with TS. While only a minority of patients with TS suffer from full blown OCD according to DSM (around 30\%, however numbers range from $2 \%$ to $66 \%$ depending on the sample investigated $^{1,4,5,25}$ ), a large number of patients (about $60-70 \%^{1,26}$ ) exhibit mild to moderate OCB. ${ }^{5}$
Importantly, several lines of evidence suggest that tics and OCD share a common pathophysiology. ${ }^{5,27}$ Both conditions have familial nature, but while $\mathrm{OCB} / \mathrm{OCD}$ is found more frequently in females, ${ }^{28}$ tics are far more common (3-4:1) in males. ${ }^{29}$ Interestingly, genetic studies indicate that $\mathrm{OCB} / \mathrm{OCD}$ and TS share a common genetical background. ${ }^{30-32}$ Como et $\mathrm{al}^{33}$ even suggested that $\mathrm{OCB}$ is an alternative expression of the TS phenotype, more commonly affecting female gene carriers. This presumed overlap is also reflected in the clinical manifestation making differentiation between tics and OCDderived symptoms sometimes very challenging.

When comparing pure $\mathrm{OCB} / \mathrm{OCD}$ in the absence of tics with comorbid $\mathrm{OCB} / \mathrm{OCD}$ in the context of TS, a number of differences emerge. Leckman et $\mathrm{al}^{34}$ conducted a crosssectional study aimed to investigate tic-related and non-tic -related OCD. They investigated 177 patients with OCD, of whom 56 had tic-related OCD. Patients with tic-related OCD more often suffered from obsessions with aggressive, religious, and sexual thoughts as well as compulsions with checking, counting, ordering, touching, and hoarding behaviors compared to those with pure OCD (without tics). Surprisingly, these two groups did not differ regarding the presence of "just right" phenomena. George et al ${ }^{35}$ prospectively assessed OCD in 10 patients with pure OCD

Table I Most Widely Used Scales in the Diagnosis and Assessment of Tics Adopted from Martino et al. ${ }^{15}$ (Listed in Alphabetical Order)

\begin{tabular}{|l|c|c|l|c|}
\hline Scale & \multicolumn{1}{c|}{$\begin{array}{c}\text { Mode of } \\
\text { Administration }\end{array}$} & $\begin{array}{c}\text { Age } \\
\text { Group }\end{array}$ & \multicolumn{1}{c|}{$\begin{array}{c}\text { Bime } \\
\text { (Minutes) }\end{array}$} \\
\hline $\begin{array}{l}\text { Tic diagnosis according } \\
\text { to DSM }\end{array}$ & Interview by clinician & $\begin{array}{c}\text { Children/ } \\
\text { adults }\end{array}$ & Interview based on DSM criteria & Max. I0 \\
\hline PUTS & Self-administered & $\begin{array}{c}\text { Children/ } \\
\text { adults }\end{array}$ & $\begin{array}{l}\text { I. Sensory premonitory urges } \\
\text { 2. I0 items }\end{array}$ & Max. 5 \\
\hline TODS & $\begin{array}{c}\text { Interview by clinician or } \\
\text { filled out by the patient }\end{array}$ & $\begin{array}{c}\text { Children/ } \\
\text { adults }\end{array}$ & $\begin{array}{l}\text { I. Joint assessment of tics and main comorbid behavioral features } \\
\text { 2. I5 items }\end{array}$ & Max. 30 \\
\hline TS-CGI & Interview by clinician & $\begin{array}{c}\text { Children/ } \\
\text { adults }\end{array}$ & $\begin{array}{l}\text { I. A 7-point scale that requires the clinician to rate the severity } \\
\text { of the patient's illness at the time of assessment }\end{array}$ & Max. 10 \\
\hline STSSS & Interview by clinician & $\begin{array}{c}\text { Children/ } \\
\text { adults }\end{array}$ & $\begin{array}{l}\text { I. Comprises five factors } \\
\text { 2. Provides overall index of tic severity }\end{array}$ & Max. 10 \\
\hline YGTSS and YGTSS-R & Interview by clinician & $\begin{array}{c}\text { Children/ } \\
\text { adults }\end{array}$ & $\begin{array}{l}\text { Divided into three parts. } \\
\text { I. The first part includes a list of motor and vocal tics. } \\
\text { 2. Assessment of tics in terms of frequency, number, intensity, } \\
\text { complexity, and interference (range, 0-50). } \\
\text { 3. Assessment of overall impairment (range, 0-50) }\end{array}$ & Max. 30 \\
\hline
\end{tabular}

Abbreviations: DSM, Diagnostic and Statistical Manual of Mental Disorders; YGTSS, the Yale Global Tic Severity Scale; YGTSS-R, the revised version of the Yale Global Tic Severity Scale; TS-CGI, Tourette Syndrome Clinical Global Impression; PUTS, Premonitory Urge for Tics Scale; TODS, Tourette's Disorder Scale; STSS, Shapiro Tourette syndrome Severity Scale. 
compared to 15 patients with TS and comorbid OCD using the Yale-Brown Obsessive Compulsive Scale (Y-BOCS), the Leyton Obsessional Inventory (LOI) as well as a questionnaire targeting to differentiate between the two disorders. They found that patients with TS plus OCD demonstrated significantly more violent, sexual and symmetrical obsessions and more touching, counting, and selfinjurious compulsions. On the contrary, patients with pure OCD suffered more often from obsessive thoughts related to dirt and germs, and - as a consequence of these - more cleaning compulsions. Interestingly, patients with TSrelated OCD felt that their compulsions arouse spontaneously, while patients with pure OCD reported that their compulsions are preceded by cognitions.

Alsbrook et $\mathrm{al}^{36}$ conducted a factor analysis of "tic symptoms" in 85 patients with TS. Four significant clinical clusters were identified: (1) aggressive phenomena (eg, kicking, temper fits, argumentativeness), (2) purely motor and phonic tic symptoms, (3) compulsive phenomena (eg, touching of others or objects, repetitive speech, throat clearing), and (4) tapping and absence of grunting. Eapen et $\mathrm{al}^{37}$ reported about clinical features and associated psychopathology in 91 patients with TS and found that OCB was positively correlated with the presence of ADHD and SIB. With regard to psychopathology in adults, principal component factor analysis yielded two factors, "obsessionality" and "anxiety/depression", which accounted for $72 \%$ of the variance. Mathews et $\mathrm{al}^{38}$ presented results of the study examining clinical and genetic data of 133 individuals with TS in the intent to identify clinical/genetic clusters. Using cluster analysis, they identified two distinct groups, those with predominantly simple tics (cluster 1) and those with multiple complex tics (cluster 2). Membership in cluster 2 was correlated with increased tic severity, global impairment, medication treatment, and presence of comorbid OCB and with family history of tics, lower verbal IQ, earlier age of onset, and comorbid OCD and ADHD in the sample of Ashkenazi Jews. Another study trying to tackle the topic of diverse clinical phenotypes in TS was published by Robertson and Cavanna ${ }^{39}$ who carried out a principal component factor analytic study in 69 patients with TS. The authors identified three significant factors, accounting for approximately $42 \%$ of the symptomatic variance: Factor 1: predominantly "pure tics", Factor 2: predominantly "ADHD and aggressive behaviors", and Factor 3: predominantly "depressionanxiety-OCB and SIB". Different kinds of tics occurred in all three factors. Only frowning/raising eyebrows and sniffing/smelling loaded significantly on Factors 1 and 3. In 2010, the same group conducted a follow-up study in a larger sample of 639 patients with $\mathrm{TS}^{40}$ Using a principal component factor analysis, again three factors were identified: (1) complex motor tics and echopaliphenomena; (2) ADHD plus aggressive behaviors; and (3) complex vocal tics and coprophenomena. OCB was significantly associated with the first two factors. The three factors accounted for $48.5 \%$ of the total symptomatic variance. Similarly, Huisman van Dijk ${ }^{41}$ reported about a relationship between tics, OCB, ADHD and autism symptoms. Their analysis revealed a five-factor structure including (1) tic/aggression/symmetry, (2) OCB/compulsive tics especially related to numbers and patterns, (3) ADHD symptoms, (4) autism symptoms; and (5) hoarding/ inattention symptoms.

\section{Terminology Used to Describe Phenomena Related to Obsessive-Compulsive Behaviors in} Tourette Syndrome

Various terminologies are used to describe $\mathrm{OCB} / \mathrm{OCD}$ related phenomena in TS including OCB, obsessive-compulsive symptoms (OCS), OCD, "just right" phenomena, "not just right experiences" (NJRE), repetitive behaviors, compulsive tics, and cognitive tics. It is important to realize that these symptoms belong to the same spectrum, largely overlap and in part are used synonymously. While OCD is clearly defined according to DSM-5 as outlined above, for all other term although often used - clear and generally accepted definitions are missing. In general, a patient is diagnosed with OCB, if obsessions and/or compulsions are only of mild severity and do not fulfil diagnostic criteria for OCD.

In contrast, NJRE specifically involve sensations of "incompleteness" rather than the need to "avoid harm" as typical seen in other OCD symptoms. "Just right" experiences are related to discomfort or tension rather than anxiety. ${ }^{42}$ Interestingly, they have been reported to proceed or accompany both tics and compulsions. ${ }^{7}$ Furthermore, Leckman et $\mathrm{al}^{8}$ suggested that premonitory urges (PUs) ${ }^{43}$ that typical proceed tics in TS show similarities with "just right" sensations. Most typically, PUs are described as an itch, discomfort or pressure. It is believed that PUs make patients execute tics in response to urges. Similarly, Coles et $\mathrm{al}^{44}$ described experiences of "not just-right" in patients with pure OCD defined as a feeling of "incompleteness", if a specific mental or physical act is somehow performed 
incorrectly. Accordingly, da Silva Prado et al ${ }^{42}$ stated that we are still lacking a consensus regarding these different terminologies. Instead of using the term, PU, "just-right" and NJRE, alternatively the umbrella term "sensory phenomena" has been proposed. ${ }^{45}$

Compared to $\mathrm{OCB} / \mathrm{OCD}$, the term "repetitive behaviors" describes a far wider spectrum of symptoms including both impulsions, compulsions, stereotypies and even tics. It is used in the context of a variety of different neuropsychiatric disorders such as autism spectrum disorder (ASD), TS, OCB/OCD, schizophrenia, dementia, epilepsy, and eating disorders. In contrast, the terms "compulsive tics" and "cognitive tics" are used only in context of TS and other tic disorders. Compulsive tics are defined as "repetitive movements performed according to rules (ie, ritualistic) in response to an obsession or to reduce tension". ${ }^{46}$ They are believed to represent a specific type of complex tics that share characteristics of both tics and compulsions. In contrast, cognitive tics are defined as mental acts that bear common characteristics with tics and obsessions. ${ }^{47}$ In clinical practice, both terms compulsive and cognitive tics are used only rarely, presumably because of the not clearly defined underlying concepts. Subsequently, we discuss each of these phenomena in more detail. Finally, also SIB in TS should be differentiated as a part of the spectrum on the verge between tics and $\mathrm{OCB} / \mathrm{OCD}$ as previous studies have demonstrated that autoaggression in TS is mainly associated with tics or OCD spectrum. ${ }^{48,49}$

\section{“Just Right” Phenomena: NJRE}

The term "just right" has been introduced for the first time in the context of OCD by Janet in 1903 in his work "Les Obsessions et La Psychasthe" describing the following phenomenon: "The patients feel that actions they perform are incompletely achieved, or that they do not produce the sought for satisfaction". ${ }^{50}$ In 1994, Leckman et $\mathrm{al}^{8}$ were the first, who used the term of "just right" sensations in the context of TS. Today, it is generally accepted that "just right" phenomena represent the most common OCB in patients with TS. They are defined as the execution of an action in a certain way in order to achieve internal relief. ${ }^{8,51}$ In 2013, Neal and Cavanna ${ }^{51}$ alternatively introduced the term "not just right experience" (NJRE) in TS research after this term has been used since 1992 in studies related to OCD. ${ }^{52}$ Although semantically more accurately compared to the term "just right", the synonym NJRE is less commonly used in TS research.
Leckman et $\mathrm{al}^{8}$ carried out a cross-sectional study in 134 subjects aged 9 to 71 to evaluate "just right" phenomena in patients with tic disorders. While $81 \%$ of patients with TS and comorbid OCD reported on a need to perform compulsions until a feeling of "just right" is achieved, only $56 \%$ of those with TS and comorbid OCB experienced such as feeling. Most of the patients described these sensations as a visual or tactile feature of the compulsion. Because of this overlap, the authors speculated that brain regions involved in sensorimotor processing are also involved in the pathophysiology of tics. In a large singlecenter study including 1032 patients with tic disorders, $10 \%$ and $62 \%$ were diagnosed with $\mathrm{OCD}$ and $\mathrm{OCB}$, respectively (based on a structured clinical interview) with NJREs being the most common symptom followed by checking, ordering, washing, and counting. ${ }^{1}$

Neal and Cavanna ${ }^{51}$ for the first time used the "Not Just Right Experiences Questionnaire-Revised" (NJREQR) to systematically investigate NJRE in 71 adults with TS. This scale was originally introduced by Coles et $\mathrm{al}^{53}$ to assess NJREs in patients with OCD. They found that $80 \%$ of patients with TS report at least one NJRE. However, patients with comorbid OCB/OCD experienced significantly more NJREs compared to those without. The strongest correlation was found between NJRE-QR scores and self-report measures of compulsivity. The authors' final conclusion was that NJREs are presumably more related to OCD than to tics. This hypothesis is in line with results of studies in pure OCD reporting an incidence of $95 \%$ of NJREs in OCD patients. ${ }^{44,54,55}$

Taken together, the clinical spectrum of OCB in patients with TS is broad. In any case, it is vital to actively inquire about OCB-related phenomena in order not to overlook these symptoms, particularly, because patients often do not report about it spontaneously. This procedure is of clinical importance, since "full blown" OCD often impairs patients' quality of life to a greater extent than the tics. Compared to pure OCD, patients with TS and comorbid OCB/OCD more frequently suffer from "just right" phenomena, which is the most typical OCB in TS. More precisely, we suggest to use the term NJRE.

\section{Repetitive Behaviors Related to Tourette Syndrome} Cath et $\mathrm{al}^{56}$ investigated the relationship between types and severity of repetitive behaviors in patients with TS plus OCD and pure OCD. They enrolled 14 subjects with TS and comorbid OCD, 18 with "TS only" (without comorbidities), 21 with pure OCD, and 29 healthy 
controls. Across the study groups, obsessions were more severe than impulsive behaviors and compulsions. Compared to pure OCD, patients with TS and comorbid OCD reported more "Tourette-related" impulsions such as mental play, echophenomena, impulsive, and SIB, but less obsessions and particular types of compulsions including washing. The authors concluded that patients with TS and comorbid OCD are phenomenologically more similar to TS than to pure OCD. Banaschewski et $\mathrm{al}^{57}$ analyzed data of a worldwide database on TS including 4833 individuals. OCB co-occurring with TS was associated with impulsive and aggressive behavior as well as with depression and anxiety. Worbe et $\mathrm{al}^{58}$ studied 166 patients with TS aged 15-68 to investigate whether repetitive behaviors represent a manifestation of OCD or belong to the tic spectrum. In their cohort, they found repetitive behaviors in $65 \%$ of patients. Based on clinical phenomenology, they identified three types of repetitive behaviors: a "tic-like" type (in $24 \%$ of patients) presenting with symptoms such as touching, counting, "just right", and symmetry; an "OCD-like" type (in $20 \%$ of patients), manifesting with repetitive behaviors such as washing and checking rituals; and finally, a "mixed group" suffering from both "tic-like" and "OCD-like" types of repetitive behaviors (in 13\% of patients). Only $6 \%$ of patients could not be classified in any of these groups. The authors concluded that in TS, different types of repetitive behaviors can be distinguished: "tic-like" behaviors, which seem to be an integral part of TS and "OCD-like" behaviors correlating with a higher score of complex tics and more frequent treatment with antipsychotics and selective serotonin reuptake inhibitors (SSRIs) as well as worse socio-professional functioning.

Eddy and Cavanna ${ }^{59}$ reviewed the literature in order to explore the nature of TS and OCD in more detail. They suggest that both disorders represent a continuum with contamination worries being more indicative for "fullblown" OCD, while repetitive behaviors are more linked to echophenomena, ordering, symmetry, and counting as typically seen in TS. Based on their research it is less clear, whether there is a difference between OCD- and TS- specific checking behaviours. They also postulate that patients with OCD are mainly focused on avoiding harm as much as possible, while in patients with TS repetitive behaviors such as self-defeat and SIB (eg, touching very hot or sharp objects) or socially dangerous acts (ie, non-obscene socially inappropriate symptoms, NOSI) are more characteristic.
All in all, distinction between "tic-like" and "OCDlike" repetitive behaviors can be very challenging. However, "tic-like" repetitive behaviors are usually preceded by premonitory urges, are ego-syntonic, and are not accompanied by intrusive thoughts, while "OCD-like" repetitive behaviors are typically anxiety-driven, are accompanied by obsessions, and are ego-dystonic.

\section{Compulsive Tics}

According to Palumbo and Kurlan, ${ }^{46}$ compulsive tics represent repetitive behaviors in patients with TS that comprise features of both compulsions and complex tics making it impossible to classify the particular symptom either as a tic or as a compulsion. Alternatively to the term compulsive tics, they suggested the term "compultics". Thus, compulsive tics are defined as repetitive movements performed according to rules, in response to an obsession, or to reduce tension, for example touching a door a certain number of times. The author highlight that compulsive tics most typically have to be performed according to specific rules, ritualistic behaviors, in a certain number of times, in a certain order or at a certain time of day (eg, bedtime rituals).

To distinguish tics from compulsions, a thorough clinical interview may be helpful: While compulsions aim at neutralizing an anxiety-driven worry, compulsive tics are not executed with the aim of anxiety reduction. Instead, they help to neutralize the feeling of sensory discomfort until a "just right" feeling is achieved or a "not just right feeling" is diminished. Whilst tics usually start at age of 5-7 and tend to exacerbate in the adolescence and decrease during adulthood, OCD initiates at the age of 10-12 and patients often experience symptom deterioration while getting older. ${ }^{60}$

\section{Cognitive Tics}

Some researchers postulate the existence of so-called "cognitive tics" or "mental tics" (both terms are used synonymously), a symptom resembling obsessions. ${ }^{47,61}$ In $2005, \mathrm{O}^{\prime}$ Connor ${ }^{62}$ first suggested the presence of cognitive tics. In his article, he defined cognitive tics as thoughts, phrases, urges, songs, words, and scenes that intrude into consciousness, are difficult to remove, and consecutively cause irritation to the person. Until today, it is a matter of discussion, whether this is a meaningful concept as by definition tics are classified as motor or vocal phenomena. However, obsessions are defined as coherent doubts or images about aversive events or 
Table 2 Similarities and Disparities Between Tics and Compulsions/Obsessions

\begin{tabular}{|l|c|}
\hline Tics & Compulsions/Obsessions \\
\hline Differences & Ritualized \\
\hline Sudden, short (jerking) & Goal-directed behavior \\
\hline Fragmented movements & Thoughts/imaginations (cognitive emotional dissonance) \\
\hline Sensorimotor urges & Mostly related to anxiety \\
\hline Not related to anxiety & Voluntary (cyclic) \\
\hline Ego-syntonic & Onset after primary school \\
\hline Involuntary (clustered sequence) & Little changes over time \\
\hline Onset in primary school (one peak) & Never during sleep \\
\hline Waxing and waning (from days to months) & Decrease with concentration \\
\hline Also during sleep & Increase with emotional excitement \\
\hline Similarities & Suppressible (long-term) \\
\hline Decrease with concentration & \\
\hline Increase with emotional excitement & \\
\hline Suppressible (short-term) & \\
\hline
\end{tabular}

thoughts, while cognitive tics are neutral or pleasant or even stimulating. Accordingly, obsessions are part of the OCB/OCD spectrum and - in the patients' mind - are linked to bad consequences. In contrast, cognitive/mental tics are isolated sequences unrelated to any consequences.

Alternatively, cognitive tics could be interpreted as a part of a much broader spectrum of intrusive thoughts defined as thoughts, images or impulses that (1) interrupt an ongoing activity, (2) are of internal attribution, and (3) are difficult to control. ${ }^{63}$ Based on this concept, the authors suggest that intrusive thought and cognitive tics share a number of common characteristics: (1) they are generally conceptualized as unwanted, (2) are hardly ever considered a one-time occurrence, but rather refer to thoughts, images, or impulses that have the tendency to repeat themselves, and (3) they have intrusive nature, which means that they interrupt regular activity.

The construct of cognitive tics is another example that illustrates the overlap of tics and obsessions and the difficulties to differentiate one from the other. In patients reporting impairing cognitive tics, treatment-specific response - to either (selective) serotonin-reuptake inhibitors ((S)SRI) or antipsychotics - may facilitate the final diagnosis of either a tic-related or an OCD-related symptom. Common and distinguishing features of tics and obsessions/compulsions are summarized in Table 2.

\section{Self-Injurious Behavior (SIB)}

Another phenomenon on the frontier between tics and compulsions is SIB found in about $40 \%$ of patients with TS. ${ }^{1,48,49,64,65}$ SIB is defined as auto-aggressive behavior directed against oneself. It is carried out although its senselessness and the risk of injury are recognized. SIB either consists merely of an urge to injure oneself against one's will or are accompanied by actual damage to one's own body against one's will. Thus, injuries caused by auto-aggressive actions are not accidental and SIB is not accompanied by suicidal intent. Until today, it is unclear whether SIB is more related to tics or to OCD or represents an independent phenomenon. From previous studies it is suggested that SIB is associated with both complex motor tics and coprophenomena, but also different psychiatric comorbidities. ${ }^{1,48,49}$ In a recent study, our group ${ }^{66}$ developed a specific diagnostic instrument for rating complexity and severity of SIB in patients with TS, the Selfinjurious Behaviour Scale (SIBS). In a large sample, 103 of 123 adult patients (84\%) reported SIB. Remarkably, SIBS scores correlated with tic severity as assessed by the Adult Tic Questionnaire (ATQ), but not with the 
severity of OCD or any other psychiatric comorbidity (unpublished data). From these results therefore it is suggested that SIB represents a specific type of tic rather than an OCD-related phenomenon.

SIB must be differentiated from severe and/or complex motor tics that cause physical impairment (eg, because of the intensity or high frequency of the tics). In addition, harm caused by OCD with excessive washing and grooming must be differentiated. Finally, also impulsive behavior related to ADHD and rage attacks may result in physical injury that must be differentiated from SIB. ${ }^{48}$

\section{Scales Used for the Diagnosis and Assessment of Obsessive-Compulsive Disorder}

According to ESSTS guidelines, ${ }^{9}$ it is recommended to actively inquire about psychiatric comorbidities in every patient with TS as type and severity of clinical symptoms determine the therapeutic approach. Although in any case the diagnostic interview should cover the whole spectrum of common comorbid disorders, it should be oriented differently depending on the patient's age. While in children the primary focus should be on ADHD followed by ASD, oppositional defiant disorder (ODD), learning disorders, anxiety disorders, and rage attacks, in adults predominant comorbidities are $\mathrm{OCB} / \mathrm{OCD}$ and mood disorders followed by anxiety disorders, ADHD, rage attacks, and SIB.

For diagnosing comorbid OCB/OCD we recommend to use DSM-5 criteria, but also structured interviews can be used, particularly, the Mini International Neuropsychiatric Interview, ${ }^{67}$ the Structured Clinical Interview for DSM Disorders $(\mathrm{SCID})^{68}$ in adults, the Mini-International Neuropsychiatric Interview for Children and Adolescents (MINI KID), ${ }^{69}$ and the Schedule for Affective Disorders and Schizophrenia for School Aged Children-Present and Lifetime Version (K-SADS-PL) ${ }^{70}$ for children, respectively. When it comes to further evaluation of $\mathrm{OCB} / \mathrm{OCD}$, the best investigated, most widely used, and, therefore, recommended scale is the Y-BOCS ${ }^{71}$ and equivalently, for children, the Children's Yale-Brown Obsessive Compulsive Scale (CYBOCS). ${ }^{72}$ Y-BOCS and CY-BOCS are 10-item, clinicianadministered scales created to rate symptom severity, but not to establish a diagnosis. They contain symptom checklists and provide five rating dimensions for both obsessions and compulsions: time spent or occupied, interference with functioning or relationships, degree of distress, resistance, and control (ie, success in resistance). Each item is rated from 0 , meaning "no symptoms", to 4 , "extreme symptoms". As the (C)Y-BOCS is considered the gold standard for the assessment of $\mathrm{OCB} / \mathrm{OCD}$, we strongly encourage to use this scale in clinical practice. However, a number of other validated and well-established rating scales is available including the Obsessive-Compulsive Inventory (OCI) ${ }^{73}$ and the OCI-Child Version, ${ }^{74}$ the LOI $^{75}$ and the LOI - Child Version Survey, ${ }^{76}$ and the Children's Obsessional Compulsive Inventory (CHOCI). ${ }^{77}$ Scales helpful in the diagnosis and assessment of OCB/OCD in patients with TS are summarized in Table 3.

While in the context of clinical studies, use of wellestablished standardized assessments is of utmost importance, in daily clinical routine practice, a structured interview represents the gold standard to capture the whole clinical symptom spectrum. Up to now, none of the available measurements can be used to unequivocally classify phenomena on the borderline between tics and OCB/OCD as one of these. Unfortunately, "tic-like" as well as "OCD-like" repetitive behaviors are included in rating scales for both tics and $\mathrm{OCB} / \mathrm{OCD}$ including the gold standard measurements. For example, SIB is mentioned in the symptom lists of both YGTSS and Y-BOCS. In other words, up to now differentiations between one and the other solely relies on clinical judgement. This in turn underlines the importance of centers of excellence for TS with extensive clinical experience. For all clinicians treating patients with TS, it is of importance to know that tics and OCB/OCD often co-occur. Not quite rarely, patients themselves may be able to assist disentangling "tic-like" from "OCD-like" repetitive behaviors, when comparing the phenomenon at issue to unequivocal tics (such as eye blinking) or unequivocal OCB/OCD (such as checking). Finally, treatment-specific response to either SSRI or antipsychotics may help to make the final diagnosis.

\section{Treatment of Tics and Comorbid Obsessive-Compulsive Disorder in Patients with Tourette Syndrome}

It is important to bear in mind that comorbidities - and in particular comorbid OCD - often cause greater impairment in patients' quality of life than tics. ${ }^{78-81}$ In general, treatment of $\mathrm{OCB} / \mathrm{OCD}$ in patients with coexisting tics/TS is based on the same premises as the treatment of patients with (pure) OCD without tics. Unfortunately, until today there is no treatment known that improves both tics and OCB/OCD. Regarding behavioral therapy (BT), for the treatment of $\mathrm{OCB} / \mathrm{OCD}$, Exposure and Response Prevention (ERP) is preferred, ${ }^{82,83}$ while in the therapy of tics Cognitive Behavioral Intervention for Tics (CBIT) is recommended. ${ }^{84,85}$ Alternatively, for 
Table 3 Most Often Used Scales in the Diagnosis and Assessment of OCD (Listed in Alphabetical Order)

\begin{tabular}{|c|c|c|c|c|}
\hline Scale & Mode of Administration & $\begin{array}{l}\text { Group } \\
\text { Examined }\end{array}$ & Brief Description of the Scale & $\begin{array}{c}\text { Time } \\
\text { (Minutes) }\end{array}$ \\
\hline $\mathrm{CHOCl}$ & Parent report & Children & $\begin{array}{l}\text { a 32-item, two-part measure assessing the content and severity of } \\
\text { compulsions and obsessions }\end{array}$ & Max. 30 \\
\hline CY-BOCS & $\begin{array}{l}\text { Administered by the clinician or } \\
\text { the parents and the child (patient } \\
\text { version) }\end{array}$ & Children & $\begin{array}{l}\text { Semi-structured interview made up of } 10 \text { items rated on a } 5 \text {-point } \\
\text { Likert scale evaluating the severity of obsessions and compulsions } \\
\text { across five dimensions, frequency, interference, distress, resistance, } \\
\text { and control(range } 0-40 \text { ) }\end{array}$ & Max. 50 \\
\hline $\begin{array}{l}\text { Kiddie- } \\
\text { SADS-PL }\end{array}$ & Administered by the clinician & Children & $\begin{array}{l}\text { A semi-structured interview aimed at early diagnosis of affective } \\
\text { disorders such as depression, bipolar disorder, and anxiety disorder }\end{array}$ & Max. 60 \\
\hline LOI-CV & Administered by the clinician & Children & $\begin{array}{l}20 \text { items are initially rated for their presence or absence; for those } \\
\text { items endorsed as present, a follow-up question assesses } \\
\text { interference caused by the symptom on a 4-point scale with higher } \\
\text { ratings representative of greater symptom severity. }\end{array}$ & Max. 20 \\
\hline MINI & Administered by the clinician & Adults & A semi-structured interview according to DSM and ICD-10 criteria & Max. 60 \\
\hline $\begin{array}{l}\text { MINI-KID } \\
\text { OCI-R }\end{array}$ & $\begin{array}{l}\text { Administered by the clinician } \\
\text { Self-report }\end{array}$ & $\begin{array}{l}\text { Children } \\
\text { Adults }\end{array}$ & $\begin{array}{l}\text { A semi-structured interview according to DSM and ICD-10 criteria } \\
\text { Self-report scale } \\
\begin{array}{l}\text { It consists of } 18 \text { questions that a person endorses on a 5-point } \\
\text { Likert scale } \\
\text { Range } 0-72 \\
\text { Cutoff is } 21 \text { points }\end{array}\end{array}$ & $\begin{array}{l}\text { Max. } 60 \\
\text { Max. } 25\end{array}$ \\
\hline $\mathrm{OCl}-\mathrm{CV}$ & Self-report & Children & $\begin{array}{c}21 \text {-item subjectively completed instrument for the quantitative } \\
\text { assessment of OCS in children and adolescents aged from } 7 \text { to } 17 \\
\text { years. }\end{array}$ & Max. 30 \\
\hline SCID & Administered by the clinician & Adults & $\begin{array}{l}\text { The SCID is a semi-structured interview guide for making diagnoses } \\
\text { according to the diagnostic criteria published in the American } \\
\text { Psychiatric Association's Diagnostic and Statistical Manual for } \\
\text { Mental Disorders (DSM). }\end{array}$ & Max. 20 \\
\hline Y-BOCS & $\begin{array}{l}\text { Administered by the clinician or } \\
\text { the patient (patient version) }\end{array}$ & Adults & $\begin{array}{l}\text { 10-item, clinician-administered scales created to rate symptom } \\
\text { severity (range } 0-40 \text { ) }\end{array}$ & Max. 30 \\
\hline
\end{tabular}

Abbreviations: K-SADS, The Kiddie Schedule for Affective Disorders and Schizophrenia; MINI, The Mini International Neuropsychiatric Interview; MINI-KID, The MiniInternational Neuropsychiatric Interview for Children; SCID, Structured Clinical Interview for DSM Disorders; Y-BOCS, Yale-Brown Obsessive-Compulsive Scale; CYBOCS, Child Yale-Brown Obsessive-Compulsive Disorder Scale; OCI-R, Obsessive-Compulsive Inventory - Revised; OCl-CV, Obsessive Compulsive Inventory — Child Version; LOI-CV, The Leyton Obsessional Inventory - Child Version Survey; CHOCl, the Children's Obsessional Compulsive Inventory.

OCB/OCD pharmacotherapy with SSRI can be initiated, ${ }^{86-89}$ while first choice treatment for tics are antipsychotics such as aripiprazole. Since ERP and pharmacotherapy with SSRI have similar efficacy on $\mathrm{OCD},{ }^{90} \mathrm{BT}$ should be recommended as first-line treatment. If monotherapy with either ERP or pharmacotherapy is insufficient, combined treatment should be offered. If $\mathrm{OCB} / \mathrm{OCD}$ responds partially to pharmacotherapy with SSRI, alternatively, augmentation with antipsychotics such as aripiprazole can be taken into consideration. ${ }^{88,91}$ If all these interventions fail to significantly improve OCD, gradual dose up-titration of the SSRI should be considered until intolerable adverse events occur. In refractory patients experimental treatments including cannabis-based medicines ${ }^{92-99}$ and finally surgical treatment with deep brain stimulation ${ }^{100}$ may be considered.

\section{Conclusions}

All in all, OCB and OCD are one of the most frequent comorbid psychiatric symptoms co-occurring in patients with primary tic disorders including TS. Since patients often do not spontaneously report on these symptoms - either because they are unaware of the relationship to TS or they are ashamed of their behaviors and thoughts - it is recommended to actively ask all patients about obsessions and compulsions 
not only at first consultation, but also at follow-up visits. Depending on the clinical context - as well as in clinical studies - it may be helpful to assess severity of OCB/OCD using the (C)Y-BOCS. By far the most frequent and most typical obsessions in patients with TS are "just right" phenomena, which more accurately should be named NJER, followed by compulsions with violent and sexual thoughts as well as symmetrical obsessions, touching, and counting. Differential diagnosis of OCB/OCD in TS includes tics, especially complex motor tics performed in the sequence, SIB, and mental phenomena on the frontiers between tics and obsessions, called cognitive tics. In patients with impairing OCB/OCD treatment with either ERP or SSRI should be offered depending on the preference of the patient.

\section{Disclosure}

KMV has received financial or material research support from EU (FP7-HEALTH-2011 No. 278367, FP7-PEOPLE2012-ITN No. 316978) DFG: GZ MU 1527/3-1 and GZ MU 1527/3-2, BMBF: 01KG1421, National Institute of Mental Health (NIMH), Tourette Gesellschaft Deutschland e.V. Else-Kröner-Fresenius-Stiftung, GW pharmaceuticals, Almirall Hermal GmbH, Abide Therapeutics, and Therapix Biosiences. She has received consultant's honoraria from Abide Therapeutics, Boehringer Ingelheim International $\mathrm{GmbH}$, Bionorica Ethics $\mathrm{GmbH}$, CannaMedical Pharma GmbH, Canopy Grouth, Columbia Care, CTC Communications Corp., Demecan, Eurox Deutschland GmbH, Global Praxis Group Limited, IMC Germany, Lundbeck, Sanity Group, Stadapharm GmbH, Synendos Therapeutics AG, and Tilray. She is an advisory/scientific board member for CannaMedical Pharma GmbH, Bionorica Ethics $\mathrm{GmbH}$, CannaXan $\mathrm{GmbH}$, Canopy Growth, Columbia Care, IMC Germany, Leafly Deutschland GmbH, Sanity Group, Syqe Medical Ltd., Therapix Biosciences Ltd., and Wayland Group. She has received speaker's fees from Aphria Deutschland GmbH, Almirall, Cogitando GmbH, Emalex, Eurox Deutschland $\mathrm{GmbH}$, Ever pharma $\mathrm{GmbH}$, Meinhardt Congress $\mathrm{GmbH}$, PR Berater, Spectrum Therapeutics $\mathrm{GmbH}$, Takeda $\mathrm{GmbH}$, Tilray, Wayland Group. She has received royalties fromDeutsches Ärzteblatt, Der Neurologie und Psychiater, Elsevier, Medizinisch Wissenschaftliche Verlagsgesellschaft Berlin, and Kohlhammer. She served as a guest editor for Frontiers in Neurology on the research topic "The neurobiology and genetics of Gilles de la Tourette syndrome: new avenues through large-scale collaborative projects", is an associate editor for "Cannabis and Cannabinoid Research" and an Editorial Board Member of "Medical Cannabis and Cannabinoids" und "MDPI-Reports" and a Scientific board member for "Zeitschrift für Allgemeinmedizin".

The authors report no other conflicts of interest in this work.

\section{References}

1. Sambrani T, Jakubovski E, Müller-Vahl KR. New insights into clinical characteristics of Gilles de la Tourette syndrome: findings in 1032 patients from a single German center. Front Neurosci. 2016;10:415. doi:10.3389/fnins.2016.00415

2. Robertson MM, Eapen V, Singer HS, et al. Gilles de la Tourette syndrome. Nat Rev Dis Primers. 2017;3(1):16097. doi:10.1038/ nrdp. 2016.97

3. Levine JLS, Szejko N, Bloch MH. Meta-analysis: adulthood prevalence of Tourette syndrome. Prog Neuropsychopharmacol Biol Psychiatry. 2019;95:109675. doi:10.1016/j. pnpbp.2019.109675

4. Scharf JM, Miller LL, Gauvin CA, Alabiso J, Mathews CA, BenShlomo Y. Population prevalence of Tourette syndrome: a systematic review and meta-analysis. Mov Disord. 2015;30 (2):221-228. doi:10.1002/mds.26089

5. Hirschtritt ME, Lee PC, Pauls DL, et al. Lifetime prevalence, age of risk, and genetic relationships of comorbid psychiatric disorders in Tourette syndrome. JAMA Psychiatry. 2015;72 (4):325-333. doi:10.1001/jamapsychiatry.2014.2650

6. Singer HS. Tics and Tourette syndrome. Continuum (Minneap Minn). 2019;25(4):936-958. doi:10.1212/CON.0000000000000752

7. Martino D, Ganos C, Pringsheim TM. Tourette syndrome and chronic tic disorders: the clinical spectrum beyond tics. Int Rev Neurobiol. 2017;134:1461-1490.

8. Leckman JF, Walker DE, Goodman WK, Pauls DL, Cohen DJ. "Just right" perceptions associated with compulsive behavior in Tourette's syndrome. Am J Psychiatry. 1994;151 (5):675-680.

9. Cath DC, Hedderly T, Ludolph AG, et al. European clinical guidelines for Tourette syndrome and other tic disorders. Part I: assessment. Eur Child Adolesc Psychiatry. 2011;20(4):155-171. doi:10.1007/s00787-011-0164-6

10. Zapparoli L, Macerollo A, Joyce EM, Martino D, Kilner JM. Voluntary tic suppression and the normalization of motor cortical beta power in Gilles de la Tourette syndrome: an EEG Study. Eur J Neurosci. 2019;50(12):3944-3957. doi:10.1111/ejn.14548

11. Bloch MH, Leckman JF. Clinical course of Tourette syndrome. J Psychosom Res. 2009;67(6):497-501. doi:10.1016/j.jpsychores. 2009.09.002

12. Groth C, Skov L, Lange T, Debes NM. Predictors of the clinical course of Tourette syndrome: a Longitudinal Study. J Child Neurol. 2019;34(14):913-921. doi:10.1177/ 0883073819867245

13. Groth C, Mol debes N, Rask CU, Lange T, Skov L. Course of Tourette syndrome and comorbidities in a Large Prospective Clinical Study. J Am Acad Child Adolesc Psychiatry. 2017;56 (4):304-312. doi:10.1016/j.jaac.2017.01.010

14. Bloch MH, Peterson BS, Scahill L, et al. Adulthood outcome of tic and obsessive-compulsive symptom severity in children with Tourette syndrome. Arch Pediatr Adolesc Med. 2006;160 (1):65-69. doi:10.1001/archpedi.160.1.65

15. Martino D, Pringsheim TM, Cavanna AE, et al. Systematic review of severity scales and screening instruments for tics: critique and recommendations. Mov Disord. 2017;32 (3):467-473. doi:10.1002/mds.26891 
16. Leckman JF, Riddle MA, Hardin MT, et al. The Yale global tic severity scale: initial testing of a clinician-rated scale of tic severity. J Am Acad Child Adolesc Psychiatry. 1989;28 (4):566-573. doi:10.1097/00004583-198907000-00015

17. Cohen SC, Leckman JF, Bloch MH. Clinical assessment of Tourette syndrome and tic disorders. Neurosci Biobehav Rev. 2013;37(6):997-1007. doi:10.1016/j.neubiorev.2012.11.013

18. Shytle RD, Silver AA, Sheehan KH, et al. The Tourette's Disorder Scale (TODS): development, reliability, and validity. Assessment. 2003;10(3):273-287. doi:10.1177/1073191103255497

19. Shapiro AK, Shapiro E. Evaluation of the reported association of obsessive-compulsive symptoms or disorder with Tourette's disorder. Compr Psychiatry. 1992;33(3):152-165. doi:10.1016/0010440X(92)90024-K

20. Woods DW, Piacentini J, Himle MB, Chang S. Premonitory Urge for Tics Scale (PUTS): initial psychometric results and examination of the premonitory urge phenomenon in youths with tic disorders. J Dev Behav Pediatr. 2005;26(6):397-403. doi:10. 1097/00004703-200512000-00001

21. McGuire JF, Piacentini J, Storch EA, et al. A multicenter examination and strategic revisions of the Yale global tic severity scale. Neurology. 2018;90(19):e1711-e1719. doi:10.1212/WNL.00000 00000005474

22. Haas M, Jakubovski E, Fremer C, et al. Yale Global Tic Severity Scale (YGTSS): psychometric quality of the gold standard for tic assessment based on the Large-Scale EMTICS Study. Front Psychiatry. 2021;12:98. doi:10.3389/fpsyt.2021.626459

23. Müller-Vahl KR, Sambrani T, Jakubovski E. Tic disorders revisited: introduction of the term "tic spectrum disorders". Eur Child Adolesc Psychiatry. 2019;28(8):1129-1135. doi:10.1007/s00787018-01272-7

24. Chen CW, Hsueh CW, Chung $\mathrm{CH}$, Wang HS, Chang HJ, Chien WC. The association between tic medication therapy and psychiatric comorbidities among patients with Tourette syndrome: a national population-based study in Taiwan. Brain Dev. 2020;42 (5):373-382. doi:10.1016/j.braindev.2020.01.002

25. Grados MA, Mathews CA. Clinical phenomenology and phenotype variability in Tourette syndrome. J Psychosom Res. 2009;67 (6):491-496. doi:10.1016/j.jpsychores.2009.07.011

26. Groth C. Tourette syndrome in a longitudinal perspective. Clinical course of tics and comorbidities, coexisting psychopathologies, phenotypes and predictors. Dan Med J. 2018;65(4).

27. Hirschtritt ME, Darrow SM, Illmann C, et al. Genetic and phenotypic overlap of specific obsessive-compulsive and attention-deficit/ hyperactive subtypes with Tourette syndrome. Psychol Med. 2018;48(2):279-293. doi:10.1017/S0033291717001672

28. Mathes BM, Morabito DM, Schmidt NB. Epidemiological and clinical gender differences in OCD. Curr Psychiatry Rep. 2019;21 (5):36. doi:10.1007/s11920-019-1015-2

29. Meoni S, Macerollo A, Moro E. Sex differences in movement disorders. Nat Rev Neurol. 2020;16(2):84-96.

30. Qi Y, Zheng Y, Li Z, Liu Z, Xiong L. Genetic studies of tic disorders and Tourette syndrome. Methods Mol Biol. 2019;2011:547-571.

31. Yu D, Mathews CA, Scharf JM, et al. Cross-disorder genomewide analyses suggest a complex genetic relationship between Tourette's syndrome and OCD. Am J Psychiatry. 2015;172 (1):82-93. doi:10.1176/appi.ajp.2014.13101306

32. Grados MA. The genetics of obsessive-compulsive disorder and Tourette syndrome: an epidemiological and pathway-based approach for gene discovery. $J$ Am Acad Child Adolesc Psychiatry. 2010;49(8):810-819, 819.e811-812. doi:10.1016/j. jaac.2010.04.009

33. Como PG, LaMarsh J, O’Brien KA. Obsessive-compulsive disorder in Tourette's syndrome. Adv Neurol. 2005;96:249-261.

34. Leckman JF, Grice DE, Barr LC, et al. Tic-related vs. non-tic-related obsessive compulsive disorder. Anxiety. 1994;1(5):208-215.
35. George MS, Trimble MR, Ring HA, Sallee FR, Robertson MM. Obsessions in obsessive-compulsive disorder with and without Gilles de la Tourette's syndrome. Am J Psychiatry. 1993;150 (1):93-97.

36. Alsobrook JP 2nd, Pauls DL. A factor analysis of tic symptoms in Gilles de la Tourette's syndrome. Am J Psychiatry. 2002;159 (2):291-296. doi:10.1176/appi.ajp.159.2.291

37. Eapen V, Fox-Hiley P, Banerjee S, Robertson M. Clinical features and associated psychopathology in a Tourette syndrome cohort. Acta Neurol Scand. 2004;109(4):255-260. doi:10.1046/j.16000404.2003.00228.x

38. Mathews CA, Jang KL, Herrera LD, et al. Tic symptom profiles in subjects with Tourette syndrome from two genetically isolated populations. Biol Psychiatry. 2007;61(3):292-300. doi:10.1016/j. biopsych.2006.02.009

39. Robertson MM, Cavanna AE. The Gilles de la Tourette syndrome: a principal component factor analytic study of a large pedigree. Psychiatr Genet. 2007;17(3):143-152. doi:10.1097/ YPG.0b013e328015b937

40. Cavanna AE, Critchley HD, Orth M, Stern JS, Young MB, Robertson MM. Dissecting the Gilles de la Tourette spectrum: a factor analytic study on 639 patients. J Neurol Neurosurg Psychiatry. 2011;82(12):1320-1323. doi:10.1136/jnnp.2010.225 029

41. Huisman-van Dijk HM, Schoot R, Rijkeboer MM, Mathews CA, Cath DC. The relationship between tics, OC, ADHD and autism symptoms: a cross- disorder symptom analysis in Gilles de la Tourette syndrome patients and family-members. Psychiatry Res. 2016;237:138-146. doi:10.1016/j.psychres.2016.01.051

42. da Silva Prado H, Do Rosário MC, Shavitt RG, Miguel EC. Sensory phenomena, "just-right" and "not just-right" experiences in OCD patients: looking for a consensus. CNS Spectr. 2007;12 (2):95-96. doi:10.1017/S1092852900020587

43. Leckman JF, Walker DE, Cohen DJ. Premonitory urges in Tourette's syndrome. Am J Psychiatry. 1993;150(1):98-102. doi:10.1176/ajp.150.1.98

44. Coles ME, Frost RO, Heimberg RG, Rhéaume J. "Not just right experiences": perfectionism, obsessive-compulsive features and general psychopathology. Behav Res Ther. 2003;41(6):681-700. doi:10.1016/S0005-7967(02)00044-X

45. Miguel EC, Coffey BJ, Baer L, Savage CR, Rauch SL, Jenike MA. Phenomenology of intentional repetitive behaviors in obsessive-compulsive disorder and Tourette's disorder. J Clin Psychiatry. 1995;56(6):246-255.

46. Palumbo D, Kurlan R. Complex obsessive compulsive and impulsive symptoms in Tourette's syndrome. Neuropsychiatr Dis Treat. 2007;3(5):687-693.

47. Piotr Janik AD, Szejko N, Jakubczyk A. Cognitive tics in Gilles de la Tourette syndrome. Res Square. 2020.

48. Szejko N, Jakubczyk A, Janik P. Prevalence and clinical correlates of self-harm behaviors in Gilles de la Tourette syndrome. Front Psychiatry. 2019;10(638). doi:10.3389/fpsyt.2019.00638

49. Mathews CA, Waller J, Glidden D, et al. Self injurious behaviour in Tourette syndrome: correlates with impulsivity and impulse control. J Neurol Neurosurg Psychiatry. 2004;75(8):1149-1155. doi:10.1136/jnnp.2003.020693

50. Janet P. Les Obsessions et La Psychasthe. Baillaire; 1903.

51. Neal M, Cavanna AE. "Not just right experiences" in patients with Tourette syndrome: complex motor tics or compulsions? Psychiatry Res. 2013;210(2):559-563. doi:10.1016/j.psychres.20 13.06.033

52. Rasmussen SA, Eisen JL. The epidemiology and clinical features of obsessive compulsive disorder. Psychiatr Clin North Am. 1992;15(4):743-758. doi:10.1016/S0193-953X(18) 30205-3 
53. Lowe DJE, Sasiadek JD, Coles AS, George TP. Cannabis and mental illness: a review. Eur Arch Psychiatry Clin Neurosci. 2019;269(1):107-120. doi:10.1007/s00406-018-0970-7

54. Nissen JB, Parner E. The importance of insight, avoidance behavior, not-just-right perception and personality traits in pediatric obsessive-compulsive disorder (OCD): a Naturalistic Clinical Study. Nord J Psychiatry. 2018;72(7):489-496. doi:10.1080/ 08039488.2018.1486454

55. Coles ME, Heimberg RG, Frost RO, Steketee G. Not just right experiences and obsessive-compulsive features: experimental and self-monitoring perspectives. Behav Res Ther. 2005;43 (2):153-167. doi:10.1016/j.brat.2004.01.002

56. Cath DC, Spinhoven P, Hoogduin CA, et al. Repetitive behaviors in Tourette's syndrome and OCD with and without tics: what are the differences? Psychiatry Res. 2001;101(2):171-185. doi:10.1016/S0165-1781(01)00219-0

57. Banaschewski $T$, Siniatchkin $M$, Uebel $H$, Rothenberger A. [Compulsive phenomena in children with tic disorder and attention deficit-hyperactive disorder]. Z Kinder Jugendpsychiatr Psychother. 2003;31(3):203-211. doi:10.1024/1422-4917.31.3.203

58. Worbe Y, Mallet L, Golmard JL, et al. Repetitive behaviours in patients with Gilles de la Tourette syndrome: tics, compulsions, or both? PLoS One. 2010;5(9):e12959. doi:10.1371/journal.pone.0012959

59. Eddy CM, Cavanna AE. Tourette syndrome and obsessive compulsive disorder: compulsivity along the continuum. J Obsessive Compuls Relat Disord. 2014;3(4):363-371. doi:10.1016/j. jocrd.2014.04.003

60. Marcks BA, Weisberg RB, Dyck I, Keller MB. Longitudinal course of obsessive-compulsive disorder in patients with anxiety disorders: a 15-Year Prospective Follow-Up Study. Compr Psychiatry. 2011;52 (6):670-677. doi:10.1016/j.comppsych.2011.01.001

61. Roberts E, Rostain AL, Samar S, Coffey BJ. Obsessional and atypical tic symptoms in an adolescent with complex Tourette's disorder and atypical pervasive developmental disorder not otherwise specified. J Child Adolesc Psychopharmacol. 2010;20 (3):219-223. doi:10.1089/cap.2010.2032

62. O’Connor K. Cognitive tics: special considerations. In: CognitiveBehavioral Management of Tic Disorders. John Wiley \& Sons; 2005.

63. Julien D, O'Connor KP, Aardema F. Intrusive thoughts, obsessions, and appraisals in obsessive-compulsive disorder: a critical review. Clin Psychol Rev. 2007;27(3):366-383. doi:10.1016/j. cpr.2006.12.004

64. Stafford M, Cavanna AE. Prevalence and clinical correlates of self-injurious behavior in Tourette syndrome. Neurosci Biobehav Rev. 2020;113:299-307. doi:10.1016/j.neubiorev.2020.03.022

65. Fischer JF, Mainka T, Worbe Y, Pringsheim T, Bhatia K, Ganos C. Self-injurious behaviour in movement disorders: systematic review. J Neurol Neurosurg Psychiatry. 2020;91 (7):712-719. doi:10.1136/jnnp-2019-322569

66. Szejko N, Lampe-Goessling $\mathrm{H}$, Pisarenko A, Haas $\mathrm{M}$, Jakubovski E, Müller-Vahl KR. Self-injurious behaviors in patients with tics - Prospective Study. In preparation.

67. Sheehan DV, Lecrubier Y, Sheehan KH, et al. The Mini-International Neuropsychiatric Interview (M.I.N.I.): the development and validation of a structured diagnostic psychiatric interview for DSM-IV and ICD-10. J Clin Psychiatry. 1998;59 (Suppl 20):22-33; quiz 34-57.

68. Shankman SA, Funkhouser CJ, Klein DN, Davila J, Lerner D, Hee D. Reliability and validity of severity dimensions of psychopathology assessed using the structured clinical interview for DSM-5 (SCID). Int J Methods Psychiatr Res. 2018;27(1):e1590. doi:10.1002/mpr. 1590

69. Sheehan DV, Sheehan KH, Shytle RD, et al. Reliability and validity of the Mini International Neuropsychiatric Interview for children and adolescents (MINI-KID). J Clin Psychiatry. 2010;71 (3):313-326. doi:10.4088/JCP.09m05305whi
70. Kaufman J, Birmaher B, Brent D, et al. Schedule for affective disorders and schizophrenia for school-age children-present and lifetime version (K-SADS-PL): initial reliability and validity data. J Am Acad Child Adolesc Psychiatry. 1997;36(7):980-988. doi:10.1097/00004583-199707000-00021

71. Goodman WK, Price LH, Rasmussen SA, et al. The Yale-brown obsessive compulsive scale. I. Development, use, and reliability. Arch Gen Psychiatry. 1989;46(11):1006-1011. doi:10.1001/ archpsyc.1989.01810110048007

72. Storch EA, McGuire JF, Wu MS, et al. Development and psychometric evaluation of the children's Yale-Brown obsessivecompulsive scale second edition. J Am Acad Child Adolesc Psychiatry. 2019;58(1):92-98. doi:10.1016/j.jaac.2018.05.029

73. Foa EB, Huppert JD, Leiberg S, et al. The obsessive-compulsive inventory: development and validation of a short version. Psychol Assess. 2002;14(4):485-496. doi:10.1037/1040-3590.14.4.485

74. Foa EB, Coles M, Huppert JD, Pasupuleti RV, Franklin ME, March J. Development and validation of a child version of the obsessive compulsive inventory. Behav Ther. 2010;41(1):1 21-132. doi:10.1016/j.beth.2009.02.001

75. Cooper J. The Leyton obsessional inventory. Psychol Med. 1970;1(1):48-64. doi:10.1017/S0033291700040010

76. Storch EA, Park JM, Lewin AB, Morgan JR, Jones AM, Murphy TK. The Leyton obsessional inventory-child version survey form does not demonstrate adequate psychometric properties in American youth with pediatric obsessive-compulsive disorder. J Anxiety Disord. 2011;25(4):574-578. doi:10.1016/j. janxdis.2011.01.005

77. Shafran R, Frampton I, Heyman I, Reynolds M, Teachman B, Rachman S. The preliminary development of a new self-report measure for OCD in young people. $J$ Adolesc. 2003;26 (1):137-142. doi:10.1016/S0140-1971(02)00083-0

78. Eapen V, Cavanna AE, Robertson MM. Comorbidities, social impact, and quality of life in Tourette syndrome. Front Psychiatry. 2016;7(97). doi:10.3389/fpsyt.2016.00097

79. Huisman-van Dijk HM, Matthijssen SJMA, Stockmann RTS, Fritz AV, Cath DC. Effects of comorbidity on Tourette's tic severity and quality of life. Acta Neurol Scand. 2019;140 (6):390-398. doi:10.1111/ane.13155

80. Rizzo R, Gulisano M, Pellico A, Calì P, Curatolo P. Tourette syndrome and comorbid conditions: a spectrum of different severities and complexities. J Child Neurol. 2014;29.

81. Kumar A, Trescher W, Byler D. Tourette syndrome and comorbid neuropsychiatric conditions. Curr Dev Disord Rep. 2016;3 (4):217-221. doi:10.1007/s40474-016-0099-1

82. Law C, Boisseau CL. Exposure and response prevention in the treatment of obsessive-compulsive disorder: current perspectives. Psychol Res Behav Manag. 2019;12:1167-1174. doi:10.2147/ PRBM.S211117

83. Team, Pediatric OCD Treatment Study POTS. Cognitive-behavior therapy, sertraline, and their combination for children and adolescents with obsessive-compulsive disorder: the Pediatric OCD Treatment Study (POTS) randomized controlled trial. JAMA. 2004;292(16):1969-1976. doi:10.1001/jama.292.16.1969

84. Verdellen C, van de Griendt J, Hartmann A, Murphy T. European clinical guidelines for Tourette syndrome and other tic disorders. Part III: behavioural and psychosocial interventions. Eur Child Adolesc Psychiatry. 2011;20(4):197-207. doi:10.1007/s00787011-0167-3

85. Pringsheim T, Piacentini J. Tic-related obsessive-compulsive disorder. J Psychiatry Neurosci. 2018;43(6):431-432. doi:10.1503/ jpn. 180086

86. Miguel EC, Shavitt RG, Ferrão YA, Brotto SA, Diniz JB. How to treat OCD in patients with Tourette syndrome. J Psychosom Res. 2003;55(1):49-57. doi:10.1016/S0022-3999(02)00583-4 
87. Roessner V, Plessen KJ, Rothenberger A, et al. European clinical guidelines for Tourette syndrome and other tic disorders. Part II: pharmacological treatment. Eur Child Adolesc Psychiatry. 2011;20(4):173-196.

88. Rothenberger A, Roessner V. Psychopharmacotherapy of obsessive-compulsive symptoms within the framework of Tourette syndrome. Curr Neuropharmacol. 2019;17(8):703-709. doi:10.2174/1570159X16666180828095131

89. Del Casale A, Sorice S, Padovano A, et al. Psychopharmacological treatment of Obsessive-Compulsive Disorder (OCD). Curr Neuropharmacol. 2019;17(8):710-736.

90. McGuire JF, Piacentini J, Lewin AB, Brennan EA, Murphy TK, Storch EA. A meta-analysis of cognitive behavior therapy and medication for child obsessive-compulsive disorder: moderators of treatment efficacy, response, and remission. Depress Anxiety. 2015;32(8):580-593. doi:10.10 02/da.22389

91. Masi G, Pfanner C, Brovedani P. Antipsychotic augmentation of selective serotonin reuptake inhibitors in resistant tic-related obsessive-compulsive disorder in children and adolescents: a Naturalistic Comparative Study. J Psychiatr Res. 2013;47 (8):1007-1012. doi:10.1016/j.jpsychires.2013.04.003

92. Milosev LM, Psathakis N, Szejko N, Jakubovski E, Muller-Vahl KR. Treatment of Gilles de la Tourette syndrome with cannabis-based medicine: results from a retrospective analysis and online survey. Cannabis Cannabinoid Res. 2019;4 (4):265-274. doi:10.1089/can.2018.0050

93. Szejko N, Fremer C, Müller-Vahl KR. Cannabis improves obsessive-compulsive disorder-case report and review of the literature. Front Psychiatry. 2020;11:681. doi:10.3389/fpsyt.2020. 00681
94. Kayser RR, Raskin M, Snorrason I, Hezel DM, Haney M, Simpson HB. Cannabinoid augmentation of exposure-based psychotherapy for obsessive-compulsive disorder. $J$ Clin Psychopharmacol. 2020;40(2):207-210. doi:10.1097/JCP.000000 0000001179

95. Kayser RR, Snorrason I, Haney M, Lee FS, Simpson HB. The endocannabinoid system: a new treatment target for obsessive compulsive disorder? Cannabis Cannabinoid Res. 2019;4 (2):77-87. doi:10.1089/can.2018.0049

96. Cooper JJ, Grant J. Refractory OCD due to thalamic infarct with response to dronabinol. J Neuropsychiatry Clin Neurosci. 2017;29 (1):77-78. doi:10.1176/appi.neuropsych.16030053

97. Muller-Vahl KR, Schneider U, Prevedel H, et al. Delta 9-tetrahydrocannabinol (THC) is effective in the treatment of tics in Tourette syndrome: a 6-week randomized trial. J Clin Psychiatry. 2003;64(4):459-465. doi:10.4088/JCP.v64n0417

98. Muller-Vahl KR, Prevedel H, Theloe K, Kolbe H, Emrich HM, Schneider U. Treatment of Tourette syndrome with delta-9-tetrahydrocannabinol (delta 9-THC): no influence on neuropsychological performance. Neuropsychopharmacology. 2003;28(2):384-388. doi:10.1038/sj.npp.1300047

99. Abi-Jaoude E, Chen L, Cheung P, Bhikram T, Sandor P. Preliminary evidence on cannabis effectiveness and tolerability for adults with Tourette syndrome. J Neuropsychiatry Clin Neurosci. 2017;29 (4):391-400. doi:10.1176/appi.neuropsych.16110310

100. Müller-Vahl KR, Cath DC, Cavanna AE, et al. European clinical guidelines for Tourette syndrome and other tic disorders. Part IV: deep brain stimulation. Eur Child Adolesc Psychiatry. 2011;20 (4):209-217. doi:10.1007/s00787-011-0166-4

\section{Publish your work in this journal}

Neuropsychiatric Disease and Treatment is an international, peerreviewed journal of clinical therapeutics and pharmacology focusing on concise rapid reporting of clinical or pre-clinical studies on a range of neuropsychiatric and neurological disorders. This journal is indexed on PubMed Central, the 'PsycINFO' database and CAS, and is the official journal of The International Neuropsychiatric Association (INA). The manuscript management system is completely online and includes a very quick and fair peer-review system, which is all easy to use. Visit http://www.dovepress.com/testimonials.php to read real quotes from published authors. 